\title{
Assessment of som (Persea bombycina) clones for resistance against Phyllosticta persae
}

\author{
Soumen Chattopadhyay ${ }^{1,2}$, Charnenko D. Sangma ${ }^{1}$, Amalendu Tikader ${ }^{1}$, Rajendra K. Rajan ${ }^{3}$ \& Bharat B. Bindroo ${ }^{2}$ \\ ${ }^{1}$ Regional Muga Research Station, Central Silk Board, Boko 781 123, Assam, India; ${ }^{2}$ Central Sericultural Research and \\ Training Institute, Berhampore 742101, West Bengal, India; ${ }^{3}$ Central Muga Eri Research and Training Institute, Central Silk \\ Board, Lahdoigarh 785 700, Assam, India
}

Author for correspondence: S. Chattopadhyay, e-mail: soumenchatto@rediffmail.com

\begin{abstract}
Som (Persea bombycina) is an economically important tree used as food source by the muga silkworm, Antheraea assamensis. Phyllactinia leaf spot (PLS), caused by Phyllosticta persae, affects all som cultivars during June to September (rainy season) and is responsible for foliage losses up to $26 \%$. Information about the effect of this disease at the farmer level and host resistance is lacking. PLS severity was assessed in six major sericulture areas of Assam, India. Furthermore, eight clones were evaluated for resistance in experimental field trials. Disease incidence and severity index (DSI), area under disease progress curve (AUDPC), apparent infection rate, lesion diameter and frequency all indicated differences among clones. DSI and AUDPC values were 3.6 fold and 4.2 fold higher in the most susceptible accession M-8 compared to M-5. High broad sense heritability $\left(h^{2}=0.80\right)$ of DSI suggested an additive nature of resistance. Correlations of DSI ( $r$ range: 0.55 to 0.91 ) with other parameters provided a good empirical evidence of obtained PLS responsiveness. M-5 showed partial resistance on the basis of all measures and appeared as the most diverse accession based on Euclidean distance. These results suggested that clone M-5 may be a potential source of resistance for use in PLS breeding programs.
\end{abstract}

Key words: Persea bombycina, Phyllosticta leaf spot, multi-parametric screening, resistant clone.

\section{INTRODUCTION}

Som (Persea bombycina Kost.), the primary food plant for the Indian golden muga silkworm (Antheraea assamensis Helfer; Lepideptera, Saturniidae), grows abundantly in the northeastern parts (latitudes, $29^{\circ} 40^{\prime} \mathrm{N}$ to $21^{\circ} 59^{\prime} \mathrm{N}$; longitudes, $89^{\circ} 29^{\prime} \mathrm{E}$ to $97^{\circ} 25^{\prime} \mathrm{E}$ ) of India (Choudhuri, 1982). The importance of this interaction is that the muga silkworm is being reared commercially for three to four lifecycles each year on the som plant for better yarn quality (Thangavelu et al., 1988). Som is infected by various pathogens that affect both the quality and quantity of leaves and in turn reduces silkworm cocoon yield. Phyllosticta leaf spot (PLS) is caused by the necrotroph Phyllosticta persae (Coelomycetes) and is becoming an increasingly important disease of som in northeastern India (Das et al., 2003). The pathogen infects a wide range of woody trees of Assam (Ali \& Saikia, 1997).

Fungi in the genus Phyllosticta (teleomorph: Guignardia or Mycosphaerella spp.) cause plant diseases such as leaf blight (Mukunya \& Boothroyd, 1972; Silva et al., 2008), gummy stem blight (Wehner \& Amand, 1993) and fruit blotch (Fischer, 2000) of various plants. The pathogen may cause serious damage to the host plant through reduced photosynthetic ability and premature leaf fall ( $\mathrm{Su} \& \mathrm{Kai}$, 2012). However in som, the sexual stage of $P$. parsae has not yet been identified. Nonetheless, the disease is easily recognized by small, irregular shaped brown or grayish brown spots scattered on the dorsal side of the moderate to full mature som leaves. As the disease progresses, the spots becomed collapsed and malformed. PLS does not kill the plants immediately, but foliage losses increase gradually with the age of plants by decreasing the functional leaf area. Because of abundant rainfall and humid tropical temperature, PLS is predominant during June-September in most of the production regions in northeastern India. Cultivars of som are very susceptible to PLS and recorded foliage loss goes up to 26\% (Das \& Das, 2008). In addition, the loss in foliage quality and the adverse impact on silkworm cocoon production are even greater (Bindroo et al., 2008).

Muga sericulture is mainly practiced by marginal/ poor growers using forest and forest fringe lands (Jolly et al., 1981) and contributes significantly to the livelihoods of tribal peoples (Singh et al., 2012). Therefore, a management strategy based on using fungicides is not a viable option. Besides, very little is known about the impact of PLS on som foliage quality at the farm level except for some basic information on the predisposing factors of the infection process (Das \& Das, 2008). Overall there is great need then to understand the impact of this disease in the field as well as identify resistance sources of som as the most costeffective and economical way of managing PLS.

This study was undertaken to evaluate the degree of severity of PLS in two main seed rearer's fields at Kamrup 
and Goalpara districts, Assam, India, and to screen available clones of som for resistance to PLS.

\section{MATERIALS AND METHODS}

\section{Survey of Phyllosticta leaf spot severity in farmers' fields}

Natural open pollinated hybrid seed orchards of som of uniform age (8-10 years) were selected. Individual sites $(\mathrm{n}=3$ from each district) were selected in the districts of Kamrup (Singra, Bolkona and Khatolpara) and Goalpara (Agia, Baida and Durapara) of Assam, along with three distinct patches of trees ( 0.2 ha each) at the Regional Muga Research Station, Boko. These locations represented the major seed crop rearing areas of muga silkworm. In each field, 20 trees were examined. The tree to tree spacing was 3 $\mathrm{m} \times 3 \mathrm{~m}$ in all fields. Two evaluations each of PLS severity were obtained during June and August of 2009 and 2010. These evaluations coincided with the 'Aherua' and 'Bhodia' muga silk moth seed crop rearing seasons in Assam that are particularly affected by PLS.

\section{Screening of som clones in experimental field}

Eight available som clones were evaluated in the experimental garden of RMRS in Boko (92 m above msl; $25^{\circ} 5^{\prime} 31^{\prime \prime} \mathrm{N}$ and $\left.91^{\circ} 24^{\prime} 00^{\prime \prime} \mathrm{E}\right)$. The experimental design was a randomized complete block with plants placed at a $3 \mathrm{~m}$ by $3 \mathrm{~m}$ spacing (Chattopadhyay et al., 2011b). Number of test plants were 20 with four replications per clone. Soil type was classified as alluvial (entisol) and having a sandy clay loam in texture with $\mathrm{pH} 7.6$, organic carbon $0.72 \%$, available $\mathrm{N}=230 \mathrm{~kg} \mathrm{ha}^{-1}$, available $\mathrm{P}=30.2 \mathrm{~kg} \mathrm{ha}^{-1}$ and available $\mathrm{K}=210.7 \mathrm{~kg} \mathrm{ha}^{-1}$ at the time of initiation of the experiment. Two split doses of inorganic $\mathrm{N}$ as urea $(87 \mathrm{~g}$ plant $\left.^{-1}\right)$, inorganic phosphorus as $\mathrm{P}_{2} \mathrm{O}_{5}\left(125 \mathrm{~g} \mathrm{plant}^{-1}\right)$ and inorganic potassium as $\mathrm{K}_{2} \mathrm{O}\left(33 \mathrm{~g} \mathrm{plant}^{-1}\right)$ were applied after each commercial harvest (June and November); application dose of farm yard manure was $10 \mathrm{~kg} \mathrm{plant}^{-1}$ during May (Chakravorti \& Barah, 2007).

\section{Disease assessment}

Twenty plants of each clone were evaluated visually using the modified logarithmic scale of Horsefall-Barrett (Horesfall \& Cowling, 1978). The scale was $0=0 \%, 1=$ $0-3 \%, 2={ }^{+} 3-6 \%, 3={ }^{+} 6-12 \%, 4={ }^{+} 12-25 \%, 5={ }^{+} 25-50 \%$, $6={ }^{+} 50-75 \%, 7=+75-88 \%, 8={ }^{+} 88-94 \%, 9=+94 \%-97 \%$ and $10=+97-100 \%$. The leaf spots were scored four times between 80 and 140 days after ground level pruning. Disease incidence (DI) was calculated as the number of leaves on the main branch with necrotic spots on a percentage basis (Gawande \& Patil, 2003). Disease severity index (DSI) was calculated for each accession according to Chattopadhyay et al. (2010). The DSI of the accessions falling in the grades 1 and 2-3 were considered as highly and moderately resistant, respectively, while those falling into 4 and $\geq 5$ were classified as intermediate and susceptible, respectively.
PLS development over time was assessed as the area under the disease progress curve (AUDPC) and the apparent infection rate (AIR). The AUDPC was calculated according to the method of Chattopadhyay et al. (2011a) using the following formula:

$$
\text { AUDPC }=\sum\left[\left(x_{i}+x_{i+1}\right) / 2\right]\left(t_{i+1}-t_{i}\right)_{i=1}^{n}
$$

where, $n$ is the number of evaluation times, $x_{i}$ is the disease intensity at evaluation time $i$ and $t_{i+1}$ is the time between two disease scores. Whereas, AIR was estimated according to the method of Rao et al. (2008) as follows:

$$
\operatorname{AIR}=\left[1 /\left(\mathrm{t}_{2}-\mathrm{t}_{1}\right)\right] \log _{\mathrm{e}}\left[\left\{\mathrm{n}_{2}\left(1-\mathrm{n}_{1}\right)\right\} /\left\{\mathrm{n}_{1}\left(1-\mathrm{n}_{2}\right)\right\}\right]
$$

where, $t_{1}=$ time during the 1 st observation; $t_{2}=$ time during the 2 nd observation; $\mathrm{n}_{1}=$ DSI at time $\mathrm{t}_{1}$ and $\mathrm{n}_{2}=$ DSI at time $t_{2}$.

Lesion sizes (LD) and lesion frequency (LF) of PLS infection were given in units of $\mathrm{mm}^{2}$ (length $\mathrm{x}$ width) and per leaf, respectively and measured 140 days after pruning from the $8-12^{\text {th }}$ leaf positions from the top according to Chaerani et al. (2007).

\section{Data analysis}

Analysis of variance was performed by using 'Statistica' version 8.0 (Statsoft Inc.). Heterogeneity in the variances was observed in the data from disease screening methods. Therefore arcsine-square root transformation was applied before analysis. Recorded data were averaged across the replicates and resulting mean scores were used for analysis. When $F$ values were significant $(P<0.05)$, Fisher's least significant differences (LSD), correlation matrix and broad sense heritability $\left(h^{2}\right)$ were calculated in appropriate cases according to Gomez \& Gomez (1984) and Jhonson et al. (1955), respectively. Furthermore, mean values for tested parameters of clones from the leaf spot screening were clustered using the same software. The Euclidean distance based on complete amalgamation rule was used to construct dendrogram using hierarchical clustering. A linkage distance of 100 was arbitrarily chosen to separate the clone into two major clusters and four subclusters in the dendrogram (Berdahl et al., 1999).

\section{RESULTS}

The severity of PLS was considered high, and also varied significantly (DSI range: 12.3 to 29.8 ) across the six villages of Kamrup and Goalpara districts, as well as in the RMRS fields of Boko over the two years of assessments (Table 1). In particular, PLS severity was significantly higher (18.5\% over respective mean seasonal DSI values) during Aherua compared to Bhodia in all fields assessed. PLS was 32\% (Aherua) and 8\% (Bhodia) higher, respectively, in Kamprup district compared to Goalpara. 
Som resources were screened multi-parametrically using qualitative and quantitative parameters like DSI, DI, AUDPC, AIR, LD and LF values. All clones showed PLS symptoms and DSI variation was 3.6-fold. The mean DSI value was 25.2 , compared to a severity index of 9.8 for M-5 (moderately resistant in H-B scale: 3 ) and 36.0 for M-8 (susceptible in H-B scale: 5) clones, respectively (Table 2). The DI variation was 4.0 -fold across the clones and the majority of them $(63 \%)$ had incidence levels over $47 \%$. The disease progress, in terms of leaf area under disease progress curve (AUDPC) between 80 to $140 \mathrm{~d}$ was also analyzed to combine multiple observations of PLS development into a singe value. There was a 3.2-fold difference between the maximum AUDPC (M-8) and the minimum (M-5), but the variation of AIR values was1.4fold across the clones. Significant variations were recorded for quantitative parameters like LD (3.2-fold) and LF (3.5fold) across the clones and like qualitative parameters, M-5 exhibited minimum values of both lesion features (Table 2).

The magnitude of variation of DI, DSI, AUDPC, LD and LF were identical (range: 3.2 to 4.1 -fold) and higher than AIR (1.4-fold). Nonetheless, all tested attributes significantly $(P<0.05)$ exhibited that M-5 and M-8 as the most resistant and susceptible clones to PLS, respectively.

Correlation analysis revealed significant associations between the parameters evaluated. A highly positive correlation of DSI was observed (Table 3$)$ with DI ( $r=0.91$; $p>0.01)$ and AUDPC $(r=0.86 ; p<0.01)$. However, the associations of AIR with DSI and AUDPC were moderate (range: $r=0.44$ to $0.56 ; p<0.05$ ) and non-significant with DI. Moreover, two measures of disease reactions, DSI and AUDPC values also showed highly significant $(\mathrm{p}<0.01)$ correlations with LD $(r=0.76$ and $r=0.68)$ and LF per leaf $(r=0.79$ and $r=0.70)$.

The strong association of DSI with DI, AUDPC, LD and LF parameters was partitioned further through hierarchical cluster analysis (Figure 1). The entries were grouped into two major clusters (A and $\mathrm{B}$ ) with a wide linkage distance of 610.5. The sub-cluster $\mathrm{A}$ was further divided into three sub-groups (A1 to A3). Relatively low responsive clones (M3, M6 and M5) were partitioned into B-1 and B-2 subgroups.

\section{DISCUSSION}

A consistently high intensity of PLS (DSI range: 18.0 to 29.8 ) in major muga silkworm seed crop rearing

TABLE 1 - Estimates of Phyllosticta leaf spot severity index (DSI ), mean square sum (MSS), variance components (VC) in different areas of Assam during 'Aherua' and 'Bhodia' seed crops. Data are mean of four field observations collected from three villages per location over two years.

\begin{tabular}{llllll}
\hline \hline Season & Location & DSI & VC & MSS & $\boldsymbol{P}<\boldsymbol{F}$ \\
\hline 'Aherua' & Kamrup & 29.8 & 5.28 & 296.64 & 0.001 \\
(June -July) & Goalpara & 20.1 & 3.17 & \\
'Bhodia' & RMRS ${ }^{1}$ & 16.3 & 2.04 & \multirow{2}{*}{153.6} & 0.01 \\
(August- September) & Kamrup & 23.2 & 4.06 & & \\
& Goalpara & 18.6 & 2.54 & & \\
& RMRS & 12.3 & 1.85 & \\
& LSD $\left(\mathrm{P}_{0.05}\right)$ & 3.2 & &
\end{tabular}

${ }^{1}$ RMRS: Regional Muga research Station.

TABLE 2 - Responses of som clones to Phyllosticta leaf spot disease at the experimental field of RMRS, Boko. Average of twenty values per clone with a total $\mathrm{df}=160$ for each parameter. Values are back transformation of arcsine $[\sqrt{ }(\mathrm{x} / 100]$.

\begin{tabular}{lcccccc}
\hline \hline Clone & DSI $^{\mathbf{a}}$ & DI & AUDPC & AIR & LD & LF \\
\hline M-1 & 25.9 & 46.9 & 752.3 & 0.030 & 37.1 & 6.7 \\
M-2 & 30.4 & 56.3 & 823.9 & 0.034 & 43.4 & 8.6 \\
M-3 & 22.3 & 41.0 & 580.8 & 0.037 & 19.9 & 4.2 \\
M-4 & 30.9 & 58.1 & 868.4 & 0.036 & 41.3 & 7.2 \\
M-5 & 9.8 & 17.0 & 287.2 & 0.026 & 14.8 & 2.9 \\
M-6 & 14.2 & 21.9 & 411.4 & 0.035 & 19.0 & 4.0 \\
M-7 & 31.8 & 59.2 & 909.0 & 0.038 & 45.6 & 9.1 \\
M-8 & 36.0 & 68.9 & 920.4 & 0.037 & 47.4 & 10.1 \\
LSD (0.05) & 3.1 & 5.2 & 60.1 & 0.007 & 4.5 & 1.1 \\
$h^{2}$ & 0.80 & & & & 0.76 & 0.61 \\
CV=15.3\% & & & &
\end{tabular}

aDSI, disease severity index; DI, disease incidence (\%); AUDPC, area under the disease progress curve (accumulative \%); AIR, apparent infection rate (unit progress/day); LD, lesion diamter $\left(\mathrm{mm}^{2}\right) ; \mathrm{LF}$, lesion frequency $\left(\right.$ no. $\left.50 \mathrm{~cm}^{2}\right)$ in the $7^{\text {th }}-10^{\text {th }}$ positioned leaves from the top after 140 days of pruning. 
TABLE 3 - Pearson correlation coefficients among qualitative and quantitative parameters of Phyllosticta leaf spot assessment.

\begin{tabular}{llllll}
\hline \hline & DSI $^{\text {a }}$ & DI & AUDPC & AIR & LD \\
\hline DI & $0.91^{* * \mathrm{~b}}$ & & & & \\
AUDPC & $0.86^{* *}$ & $0.79^{* *}$ & & & \\
AIR & $0.56^{*}$ & $0.44^{\text {ns }}$ & $0.54^{*}$ & $0.43^{\text {ns }}$ & $0.49^{\text {ns }}$ \\
LD & $0.76^{* *}$ & $0.67^{* *}$ & $0.68^{* *}$ & $0.86^{* *}$ \\
LF & $0.79^{* *}$ & $0.76^{* *}$ & $0.70^{* *}$ & $0.0 \%$ AR,
\end{tabular}

${ }^{\mathrm{a} D S I}$, disease severity index; DI, disease incidence (\%); AUDPC, area under the disease progress curve (accumulative \%); AIR, apparent infection rate (unit progress/day); $\mathrm{LD}$, lesion diamter $\left(\mathrm{mm}^{2}\right)$

b**,$*$ and ns, significant at $\mathrm{p}>0.01, \mathrm{p}>0.05$ and non-significant, respectively.

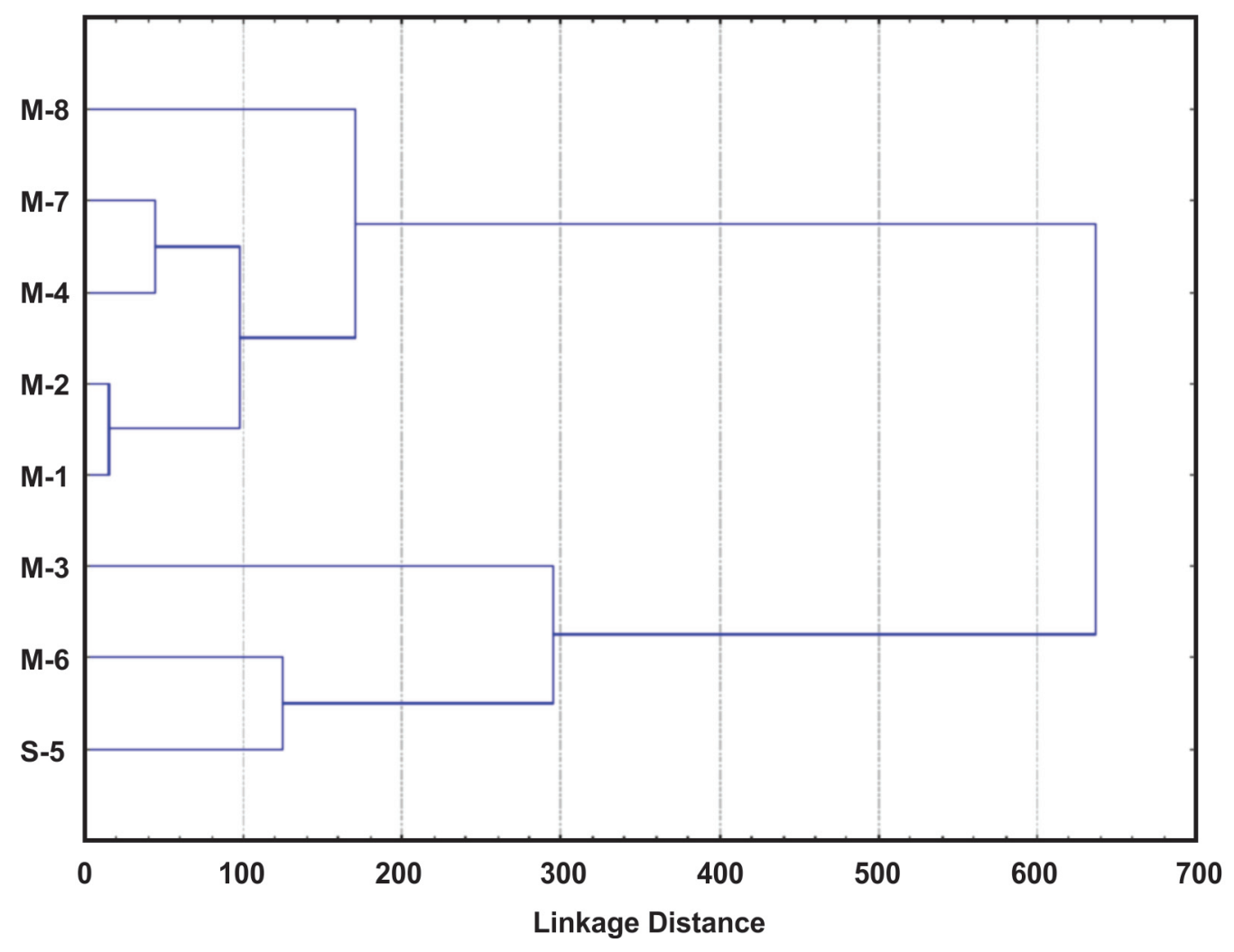

FIGURE 1 - Dendrogram of eight som clones obtained by analysis of disease severity index, disease incidence, area under the disease progress curve, apparent infection rate, lesion diameter and lesion frequency values during leaf spot infection at the experimental field of RMRS, Boko. areas of Goalpara and Kamrup districts (total: six locations) were recorded in both seasons. It has been shown that the estimated leaf yield loss of a som garden is about $4900 \mathrm{~kg}$ due to a PLS severity of 33\% during July in northeastern India (Das \& Das, 2008). We assessed PLS severity using Horsefall-Barrett (H-B) scale and recorded DSI values within the range of intermediate to susceptible grades of PLS. The relationship between the nearest percent estimate of any disease severity with $\mathrm{H}-\mathrm{B}$ scale data is linear especially within the range of 0 to $60 \%$ (Bock et al., 2010). Therefore the recorded DSI values indicated empirically that having a control measure for the disease is essential. Selected plant ages, cultural practices and climatological factors were very similar. In spite of this, the extent of symptom expression was different in two districts possibly due to differential pathogen loads in the two districts. This is the first study to document PLS severities of som across the muga sericulture villages.

Considerable levels of damage (based on DSI) due to PLS in muga seed crop rearing areas necessitated research to identify resistant clones among the available resources. A combination of qualitative (DSI, DI, AUDPC, AIR) and quantitative (LD, LF) parameters were used to assess PLS resistance. These parameters are widely used for assessment of foliar fungal disease reactions (Campbell \& Madden, 1990). Clones were ranked based on the mean PLS rating averaged over two seasonal data of two consecutive years. Although the disease reaction was assessed four times between 80 to $140 \mathrm{~d}$ after pruning (DAP) at an interval of $15 \mathrm{~d}$ (data not shown), but the magnitude of the variation of PLS response at 140 DAP justified the use of evaluating clonal differences principally at this data point. Results 
indicated that there was substantial clonal variability across the different disease parameters assessed, and while no clone was asymptomatic to PLS, clone M-5 consistently had the lowest disease ratings, indicating a potential source of resistance for further study.

From a breeding perspective, it has been suggested that the use of moderate or rate-reducing resistance may be more durable than complete resistance (Calenge et al., 2004). In the present study this was evaluated in terms of AUDPC and AIR. Although significant clonal differences were indicated by AIR (1.4-fold), a measure of the rate of disease symptom change, the difference was not as distinct as that of AUDPC (3.2-fold), a measure of cumulative disease progress over a specific study period. These findings agree with those of Meles et al. (2004) and Sillero et al. (2000) in indicating that AUDPC is more informative than AIR when assessing the level of resistance of various diseases in the field. As the rate of disease increase is jointly proportional to the level of disease and healthy tissue (Madden, 1980; Kushallappa \& Ludwig, 1981), differential leaf growth of various clones may be responsible for less variation in AIR (Pandey et al., 2003). Overall, the results showed a good agreement in the trends of all qualitative and quantitative disease parameters.

The resistant clone M-5 had the lowest DI, DSI, AUDPC and AIR values. These results are in agreement with findings in other pathosystems (Adhikari et al., 1994). However, DI and DSI revealed more distint differences (4.1fold and 3.7-fold) among the clones than other parameters. AUDPC and AIR take into account disease severity in different time spans, while DI and DSI values calculated from the single point data (here $140 \mathrm{~d}$ after DAP) are often representative of the extent of disease for a specific hostpathogen interaction (Vanderplank, 1982; Silva et al., 2013). Mean DSI and DI values indicated that adequate disease pressure was attained during field screening, and these parameters may be useful for PLS screening in som. Whereas, the AUDPC value reflected the slower development of PLS in the M-5 clone.

Additionally, two other quantitative parameters, LD and LF, were also in good agreement with the measured qualitative features. It has been shown that smaller values for LD and LF are characteristic of partial resistance (Wang \& Hartman, 1992; Twizeyimana et al., 2008). In the current study, it has been shown for the first time that the M-5 clone, which had the lowest measures of disease intensity during the entire experiment, possibly possesses partial resistance. Adding to this hypothesis is the fact that results were also consistent across two years in which natural disease intensity was relatively high. Further evidence was based on a high broad sense heritability ( $h^{2}: 80.6$ to 60.1$)$ of DSI, and quantitative disease assessment parameters like LD and LF indicating the additive nature of the resistance. Moreover, DSI was strongly correlated with DI $(\mathrm{r}=0.91 ; P>0.01)$ and AUDPC $(\mathrm{r}=0.86 ; P<0.01)$. On the other hand, correlations of AIR with DSI and AUDPC were moderate $(r=0.56$ and
0.54; $P<0.05)$ and non-significant with DI $(r=0.44 ; P<$ $0.05)$. Highly positive correlation of DSI especially with DI and AUDPC indicates that PLS could be studied by either one of these three parameters with equivalent accuracy. As the AUDPC represents the integration of all host, pathogen and environmental effects during the epidemic (Campbell \& Madden, 1990), assessment of AUDPC would be a better option than DSI and DI. Moreover, the importance of the LD and LF as indicators of resistance have not been studied so far in PLS. Highly significant positive correlations between DSI and AUDPC and quantitative parameters like $\mathrm{LD}(\mathrm{r}=0.76 ; P<0.01)$ and LF per leaf $(\mathrm{r}=0.79 ; P<0.01)$ confirmed these results and provide additional information that these two quantitative parameters could help in the selection of resistant clones.

Strong association of all disease parameters with LD and LF were further partitioned through hierarchical cluster analysis. Euclidean distance showed that the moderately resistant clone M-5 was also the most diverse accession among the tested lines. The cluster analysis largely showed good agreement among obtained disease reactions and correlative morphological features.

In conclusion, the identification of moderate resistant in accession M-5 through multi-parametric features of high heritability and sufficient genetic divergence indicate the potential use of this clone in a som breeding program for PLS resistance.

\section{ACKNOWLEDGEMENTS}

Authors are thankful to Mr. T. C. Boro for his excellent field assistance.

\section{REFERENCES}

Adhikari TB, Mew TW, Teng PS (1994) Progress of bacterial blight on rice cultivars carrying different Xa genes for resistance in the field. Plant Disease 78:73-77.

Ali MS, Saikia UN (1997) Coelomycetes of Assam. Indian Phytopathology 50:200-205.

Berdahl JD, Mayland HF, Assay KH, Jefferson PG (1999) Variation in agronomic and morphological traits among Russian wild rye accessions. Crop Science 39:1890-1895.

Bindroo BB, Sahu A, Chakravorti R (2008) Muga culture in northeastern region: Problems and prospects. Indian Silk 52:16-20.

Bock CH, Gottwald TR, Parker PE, Ferrandino F, Welham S, van den Bosch F, Parnell S (2010) Some consequences of using the Horsefall-Barratt scale for hypothesis testing. Phytopathology 100:1030-1041.

Calenge F, Faure A, Goerre M, Gebhardt C, Van de Weg WE, Parisi L, Durel CE (2004) A QTL analysis reveals both broadspectrum and isolate specific QTL for scab resistance in an apple progeny challenged with eight isolates of Venturia inaequalis. Phytopathology 94:370-379.

Cambell CL, Madden LV (1990) Introduction to Plant Epidemiology. New York, NY, USA. John Wiley \& Sons. 
Chaerani R, Groenwold R, Stam P, Voorrips RE (2007) Assessment of early blight (Alternaria solani) resistance in tomato using a droplet inoculation method. Journal of General Plant Pathology 73:96-103.

Chakravorti R, Barah UC (2007) Advances in technology research in muga culture. In: Chakravorty R, Barah A, Dutta P (Eds.) Proceedings of the workshop on current technology of muga host plants and silkworm. Lahdoigarh, India. CMER\&TI. pp. 1-13.

Chattopadhyay S, Ali KA, Doss SG, Das NK, Aggarwal RK, Bandopadhyay TK, Sarkar A, Bajpai AK (2010) Evaluation of mulberry germplasm for resistance to powdery mildew in the field and greenhouse. Journal of General Plant Pathology 76:87-93.

Chattopadhyay S, Ali KA, Doss SG, Das NK, Aggarwal RK, Bandopadhyay TK, Sarkar A, Bajpai AK (2011a) Association of leaf micro-morphological characters with powdery mildew resistance in field grown mulberry (Morus spp.). AoB Plants doi: 10.1093/aobpla/plr002.

Chattopadhyay S, Tikader A, Das NK (2011b) Nondestructive, simple, and accurate model for estimation of the individual leaf area of som (Persea bombycina). Photosynthetica 49:627-632.

Choudhuri SN (1982) Muga Silk Industry. Guwahati, India. Directorate of Sericulture, Government of Assam.

Das R, Das K (2008) Incidence of leaf spot of som (Persea bombycina) in relation to weather and chemical management. Journal of Mycology and Plant Pathology 38:322-324.

Das R, Das K, Benchamin KV (2003) Diseases of muga food plant som. Indian Silk 41:23-24.

Fisher C (2000) Multiple resistant apple cultivars and consequences for apple breeding in future. Acta Horticulturae 538:229-234.

Gawande VL, Patil JV (2003) Genetics of powdery mildew (Erysiphe polygoni DC) resistance in mungbean (Vigna radiata $\mathrm{L}$. Wilczek). Crop Protection 22:567-571.

Gomez K, GomezAA(1984) Statistical Procedures for Agricultural Research. New York, NY, USA. John Wiley \& Sons.

Horsfall JG, Cowling EB (1978) Pathometry: The measurement of plant disease. In: Horsfall JG, Cowling EB (Eds.) Plant Disease. New York, NY, USA. Academic Press. pp.120-136.

Johnson HW, Robinson HS, Constock RE (1955) Estimates of genetic and environmental variability in soybean. Agronomy Journal 47:314-318.

Jolly MS, Sen SK, Sonwalker TN, Prasad GK (1981) Agriculture Service Bulletin: Non mulberry silks. Rome, Italy. FAO.

Kushalappa AC, Ludwig A(1982) Calculation of apparent infection rate in plant diseases: Development of a method to correct for host growth. Phytopathology 72:1373-1377.

Madden LV (1980) Quantification of disease progression. Protection Ecology 2:159-176.

Meles K, Huluka M, Abang MM (2004) Phenotypic diversity in Rhynchosporium secalis from Ethiopia and host response to barley scald. Plant Pathology Journal 3:26-34.

Mukunya DM, Boothroyd CW (1972) Mycosphaerellazeae-maydis sp. N., the sexual stage of Phyllosticta maydis. Phytopathology 63:529-532.

Pandey KK, Pandey PK, Singh B (2003) Artificial screening of black rot resistance based on different disease parameters in early cauliflower. Mycobiology 31:173-178.

Rao ES, Munshi AD, Sinha P, Rajkumar S (2008) Genetics of rate limiting disease reaction to Alternaria solani in tomato. Euphytica 159:123-134.

Silva AS, Oliveria EJ, Haddad F, Laranjeira FR, Jesus N, Aliveira SAS, Carvalho MAP, Freitas PX (2013) Identification of passion fruit genotypes resistant to Fusarium oxysporum f. sp. passiflorae. Tropical Plant Pathology 38:236-242.

Silva M, Pereira OL, Braga IF, Leli SM (2008) Leaf and pseudobulb diseases on Bifrenaria harrisoniae (Orchidaceae) caused by Phyllosticta capitalensis in Brazil. Australasian Plant Disease Notes 3:53-56.

Singh YT, Mazumdar-Leighton S, Saikia M, Pant P, Kashung S, Neog K, Chakravorty R, Nair S, Nagaraju J (2012) Genetic variation within native populations of endemic silkmoth Antheraea assamensis from northeast India indicates need for in situ conservation. PLoS ONE 7:e49972.

Su YY, Cai L (2012) Polyphasic characterization of three new Phyllosticta spp. Persoonia 28:76-84.

Thangavelu K, Chakraborty AK, Bhagowati AK, Isa M (1998) Handbook of muga culture. Bangalore, India. Central Silk Board.

Twizeyimana M, Ojiambo PS, Ikotun T, Ladipo JL, Hartman GL, Bandopadhyay R (2008) Evaluation of soybean germplasm for resistance to soybean rust (Phakopsora pachyrhizi) in Nigeria. Plant Disease 92:947-952.

Vanderplank JE (1982) Host-pathogen Interactions in Plant Diseases. New York, NY, USA. Academic Press.

Wang TC, Hartman GL (1992) Epidemiology of soybean rust and breeding for host resistance. Plant Protection Bulletin 34:109124.

Wehner TC, Amand PCS (1993) Field tests for cucumber resistance to gummy seath blight in North Carolina. HortScience 28:327-329. 